\title{
China Watch
}

\section{Editorial}

With increasing re-recognition, education in China has drawn more and more global attention in recent years. China Watch is the signature column of Beijing International Review of Education, aiming at updating the international community with the latest policy move and practice improvement of education in China, featured with short articles around 2,500 words each.

Topics of China Watch include but are not limited to learning, teaching, schooling; governance, leadership or planning in education; educational evaluation (assessment); teacher education; moral or citizenship education; language education; STEM education; inclusive education; girls (women) education; vocational education; educational finance; privatization; or internationalization of education, etc., ranging from early childhood, basic to post-secondary education, from life-long to life-wide education, and/or from educational theory to practical innovation. China Watch in this special issue focuses on "Recent Studies on Dewey's Visit to China (1919-1921)".

Articles in this column usually include three core components: 1) an abstract and keywords; 2) a brief introduction about an enduring or emergent topic of education in China, and; 3 ) a disciplinary or interdisciplinary analysis about the topic. Articles are welcome to be submitted in MS Word format via email attachment to:

\author{
Prof. LIJun \\ Western University Faculty of Education, Canada \\ jun.li@uwo.ca
}

